\title{
Comparative Analysis of DITC Based Switched Reluctance Motor Using Asymmetric Converter and Four-Level Converter
}

\author{
P. Srinivas*, K. Amulya ${ }^{\star \star}$ \\ * Asst. Professor, Department of Electrical Engineering, University College of Engineering,Osmania \\ University, Hyderabad, Telanagana, India \\ ${ }^{* *}$ Research Scholar, Department of Electrical Engineering, University College of Engineering,Osmania \\ University, Hyderabad, Telanagana, India \\ Email: srinivasp.eedou@gmail.com
}

\begin{abstract}
High torque ripple is the main draw of Switched Reluctance Motor (SRM) compared to other conventional motor. Torque ripples can be minimized by Direct Instantaneous Torque Control (DITC) technique. DITC responds against the torque error instantaneously by using hysteresis torque controller and regulate the torque output of the motor within hysteresis band. This paper compares the performance of Switched Reluctance Motor in terms of torque ripples with DITC strategy for both Asymmetric converter and Four-level converter. Asymmetric converter has three states namely magnetization, freewheeling and demagnetiztion states. With four-level converter, fast magnetization and fast demagnetization are also possible. Thus, the current build up and decay time is reduced which improves the dynamic performance. SRM is simulated using DITC scheme with Asymmetric converter and Four-level converter in MATLAB/SIMULINK to analyze torque ripples and it is observed that DITC with four level converter is better than that with Assymetrical converter.
\end{abstract}

Keywords: Direct Instantaneous Torque Control, Switched Reluctance Motor, Asymmetrical converter, Four level converter

\section{Introduction}

Switched Reluctance Motor is considered as an alternate to conventional motor because of its advantages such as simple structure, high torque to inertia ratio, adapibility to hostile environment and high reliability. The disadvantage is that the torque production is nonlinear due to doubly salient structure of motor which causes torque ripple [1], [2]. In order to overcome this drawback several control strategies have been proposed, which are classified into two categories: indirect and direct torque control.

The indirect method involves using TSF in which torque ripple is minimized by applying the current profile [3], [4]. These profiles are, however, calculated offline for constant performance points at a high memory cost. Four types of torque sharing functions, which are linear, cubic, sinusoidal and exponential functions, are proposed. However, it is observed that the results depend on motor technical specifications and have to be changed in other SRM.

Direct torque control uses a simple control scheme of torque hysteresis control to reduce the torque ripple [5-8]. In this technique, torque is treated as direct control variable and is not converted to current. Depending on the torque error, hysteresis torque controller determines the mode of operation of converter in order to maintain output torque of the motor equal to the reference torque. DITC using four-level converter [9], [10] is used in order to have fast magnetization and fast demagnetization. At high speed the time for current build up and fall time is less. By using four-level converter current can be built up at a faster rate. By DITC control of four-level converter torque ripple is reduced to greater extent.

In this paper DITC technique is compared for both Asymmetric converter and Four-level converter and the results are analyzed with respect to torque ripple. 


\section{Principle of Direct Instantaneous Torque Control (DITC)}

The block diagram of DITC drive is shown in Figure 1. The actual speed is compared with the reference speed using a PI controller. The output of PI controller is reference torque. The actual torque is compared with the reference torque and the error signal is given to the torque hysteresis controller. In order to generate switching signals for the converter DITC code is written in the embedded function block. If torque generated by the motor is less, phase current is forced to increase by switching on both the switches and if torque is more than reference, current is forced to reduce by switching off single switch or both the switches of the converter. In this paper DITC technique is proposed for two converters namely Asymmetric converter and Four-level converter. Switching rules are discussed separately for each of these converters.

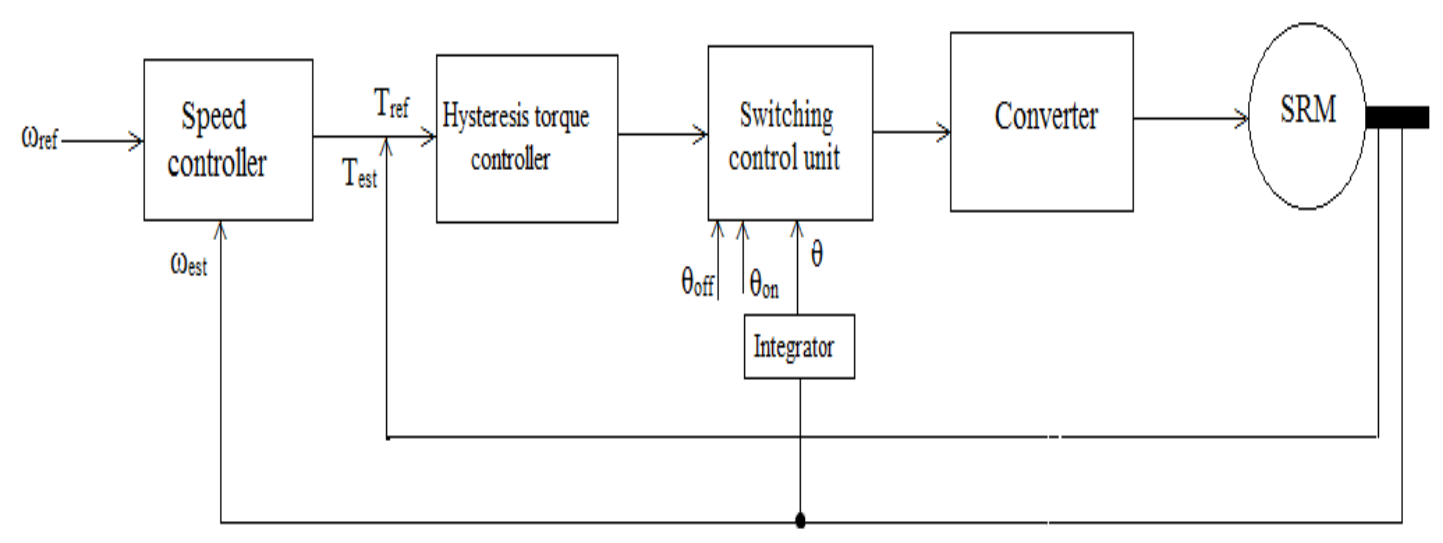

Figure 1. Block diagram of DITC

\section{DITC with an Asymmetric Converter}

The most commonly used converter for an SRM is the Asymmetric converter because of its flexibility and versatility in four quadrant operation. The advantage of Asymmetric converter is that the stator phase windings can be individually controlled; therefore drive operation is not prevented even in case of damage of any switch. Asymmetric converter operates in three modes. The modes of operation of Asymmetric converter are shown in Figure 2. When switches Q1 and Q2 are closed, the circuit takes the form shown in Figure 2(a). The positive source voltage is applied to the phase, and current flows into the phase windings such that flux increases. This mode is known as magnetization mode and is represented by state 1. When switches Q1 is open and Q2 remains closed, as in Figure 2(b), the phase is isolated from the source, diode D1 is forward biased, and the phase winding current circulates, or freewheels, inside the loop of diode D1 and switch Q2. This is the zero-voltage loop, and flux decays very slowly due to the conduction losses within the elements in that loop. This mode is known as freewheeling mode and is represented by state 0 . When switches Q1 and Q2 are both open, as in Figure 2(c), then both diodes D1 and D2 are forward biased, but the source voltage terminal polarity is switched across the phase winding, such that negative source voltage is applied to the phase. This serves to drive current, and flux, in the phase to zero quickly. This mode is known as demagnetization mode and is represented by state -1 . 


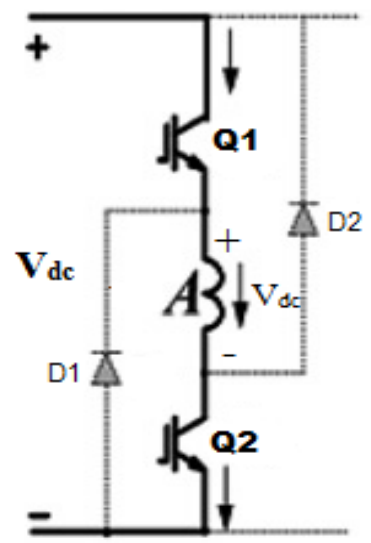

a) Magnetization mode (1)

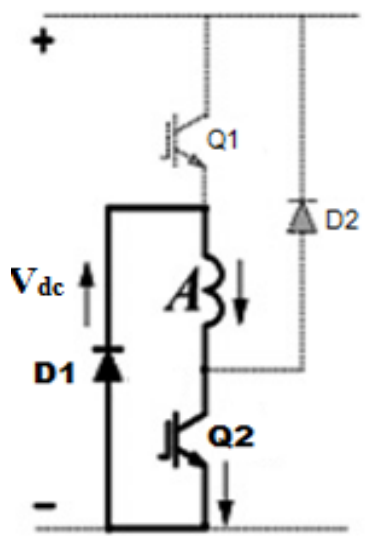

b) Freewheeling mode $(0)$

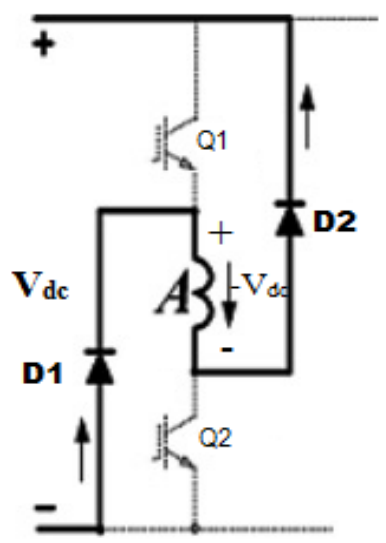

c) Demagnetization mode (-1)

Figure 2. Operation modes of the Asymmetric converter

In order to control the switching of the converter and activate the phases as required a suitable controller has to be employed. Hysteresis torque controller for an Asymmetric converter is shown in Figure 3 which generates switching signals for the converter based on error between reference torque and motor torque. Horizontal axis represents the torque error and vertical axis represents the state of Asymmetric converter. During single phase active period torque is regulated within the inner band. When torque error crosses limit $f$ torque error is positive, estimated torque is less than reference torque so state 1 is applied in order to increase phase torque. When torque error crosses limit e torque error is negative, estimated torque is greater than reference torque so sate 0 is applied in order to decrease torque [5].

During commutation period, both incoming and outgoing phases start conducting. The switching scheme for the incoming phase is identical to the scheme during the single active period. The switching scheme for outgoing phase can be summarized as follows [5]:

a. When torque error exceeds limit "a", torque error is positive which implies that estimated torque is less than the reference torque. In order to increase the torque state $1\left(+V_{d c}\right)$ is applied. b. When torque error falls below limit "b", torque error starts becoming negative which implies that estimated torque is greater than the reference torque. In order to decrease the torque state $1\left(+V_{d c}\right)$ is changed to state 0 . c. When torque error falls below limit "d", torque error is more negative compared to case 2 , which implies that estimated torque is very much greater than the reference torque. In order to decrease this high value of torque state 0 is changed to state -1 .

d. When torque error exceeds limit "c", torque error is less positive compared to case 1 , which implies that estimated torque is less than the reference torque. In order to increase the torque state $-1\left(-V_{d c}\right)$ is changed to state $0 .[5]$

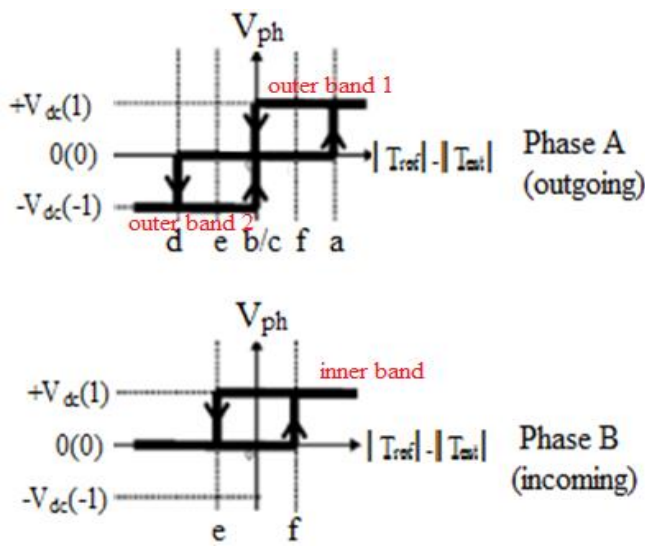

Figure 3. Switching scheme for DITC with Asymmetric converter 


\section{Simulation and Analysis of SRM Using DITC Scheme with Asymmetric Converter}

Simulation model of 4-phase 8/6 SRM using DITC scheme of Asymmetric converter is shown in Figure 4. Actual speed is compared with the reference speed and the error is given to $\mathrm{PI}$ controller. The output of $\mathrm{PI}$ controller is reference torque. Estimated torque is compared with this reference torque and the error signal is given to a hysteresis torque controller which generates switching signals for the converter based on error. Torque is regulated within two hysteresis bands. The controller block used in Figure 4 is depicted by a flow chart shown in Figure 5.

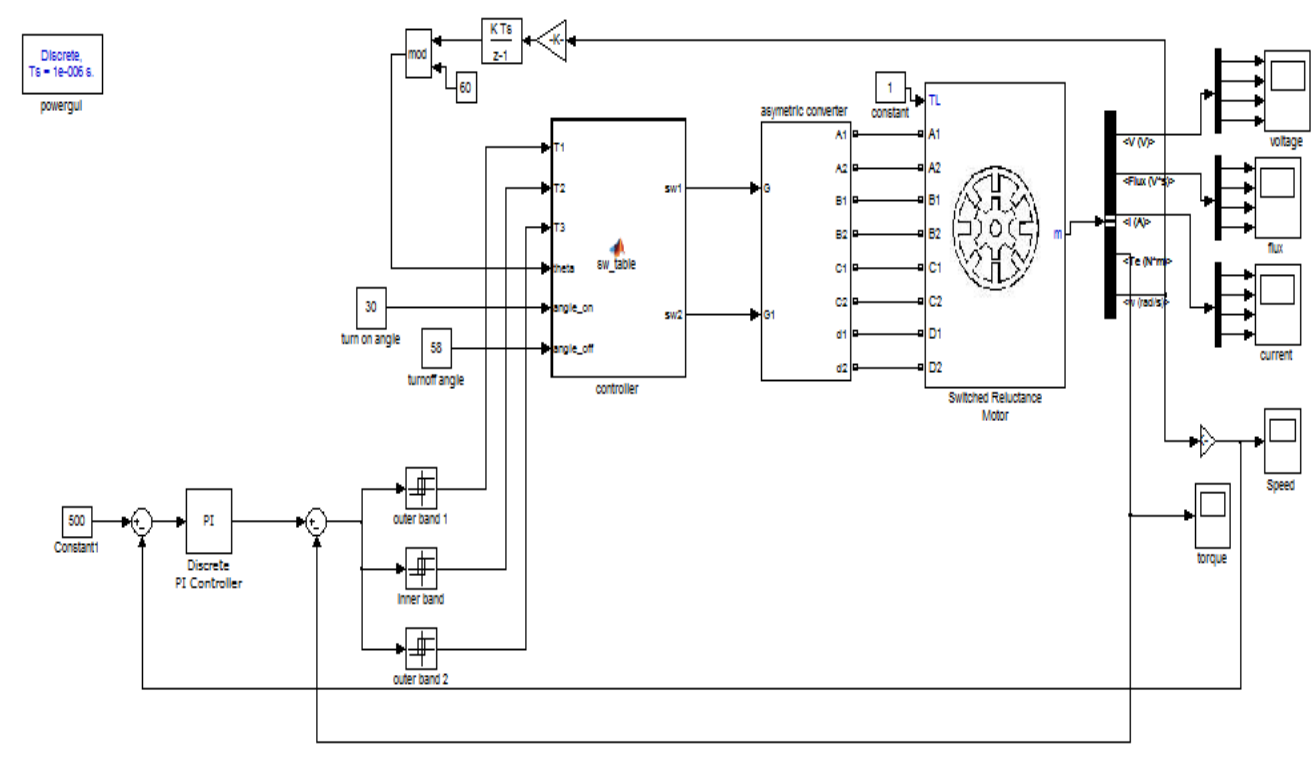

Figure 4. Simulink model of 8/6 SRM using DITC scheme of Asymmetric converter

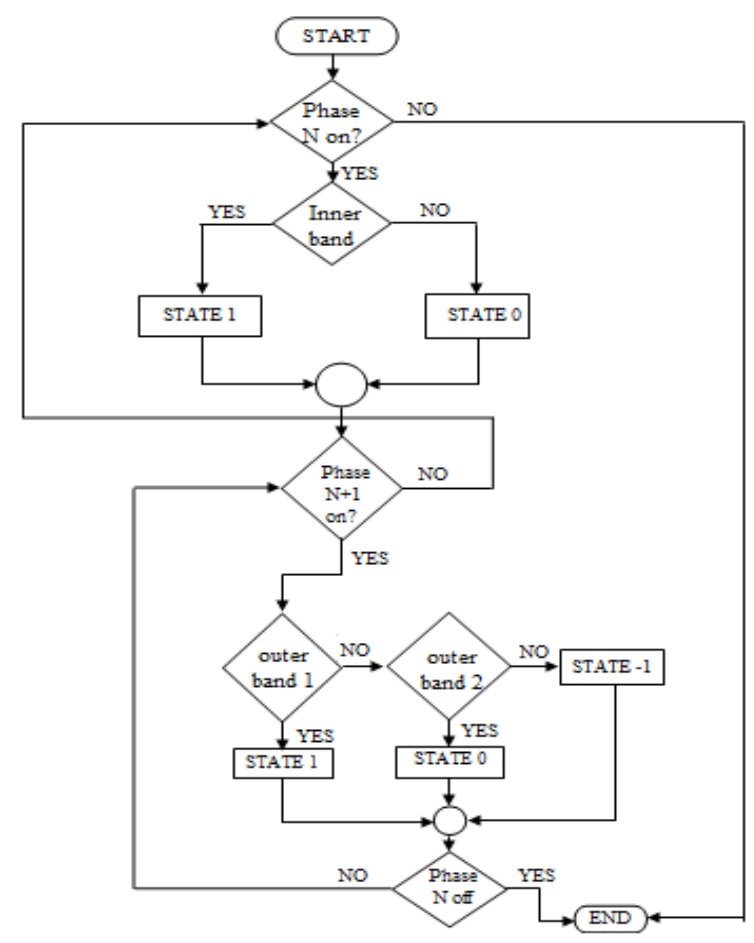

Figure 5. Flow chart representation of hysteresis torque controller for Asymmetric converter 
The performance of the DITC based SRM drive using Asymmetric converter is analyzed for a constant load torque of $1 \mathrm{Nm}$ and a reference speed of $500 \mathrm{rpm}$. Actual speed is compared with the reference speed and error is given to a PI controller. The output of PI controller is the reference torque. The PI controller output is $4 \mathrm{Nm}$ whenever the speed is less than the reference speed. When the speed reaches the reference value the PI controller output equals the load torque.

Figure 6(a) shows the total torque. The torque is maintained at $4 \mathrm{Nm}$ till the steady state is reached. When the steady state is reached it is maintained at the load torque value of $1 \mathrm{Nm}$. Torque ripple is $5 \%$ in this case. Figure $6(\mathrm{~b})$ shows the speed response. Speed increases linearly and it settles at reference speed of $500 \mathrm{rpm}$ after $0.089 \mathrm{sec}$. Figure 6(c) shows the voltages of four phases. The voltage in each phase changes between $+120 \mathrm{~V}, 0 \mathrm{~V}$ or $-120 \mathrm{~V}$ depending upon the torque error in order to maintain the total torque equal to the load torque. Figure $6(\mathrm{~d})$ shows the flux of four phases. The maximum value of flux during acceleration period is $0.25 \mathrm{~Wb}$ and in the steady state the maximum flux value is $0.08 \mathrm{~Wb}$. Figure $6(\mathrm{e})$ shows the current waveform of all the four phases. The currents and flux linkage are proportional to each other so that they will vary almost similarly with respect to time. The maximum value of current during acceleration period is $4 \mathrm{~A}$ and in the steady state the maximum current value is $1 \mathrm{~A}$.

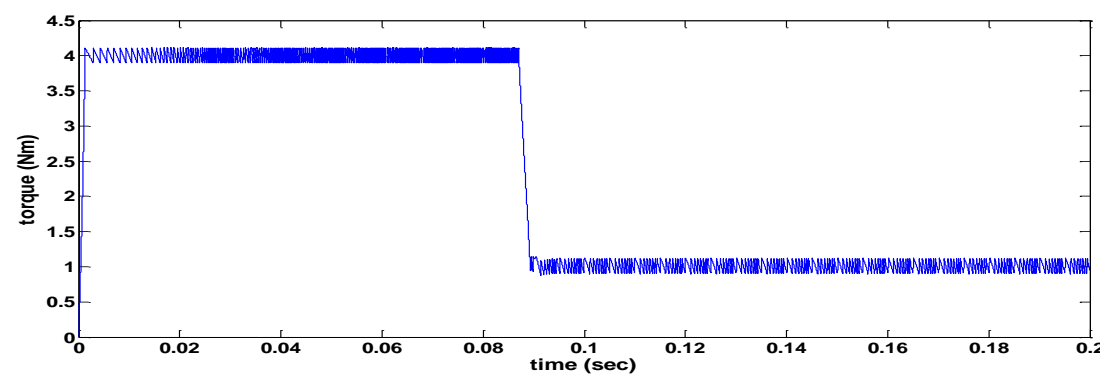

(a) Total Torque

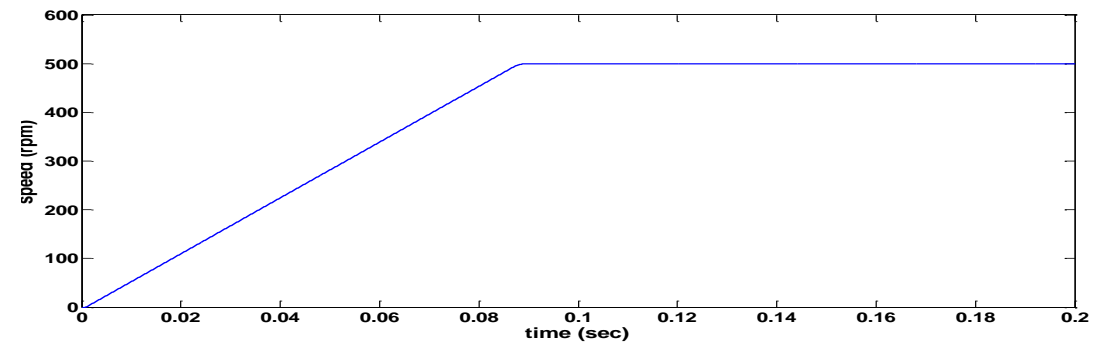

(b) Speed

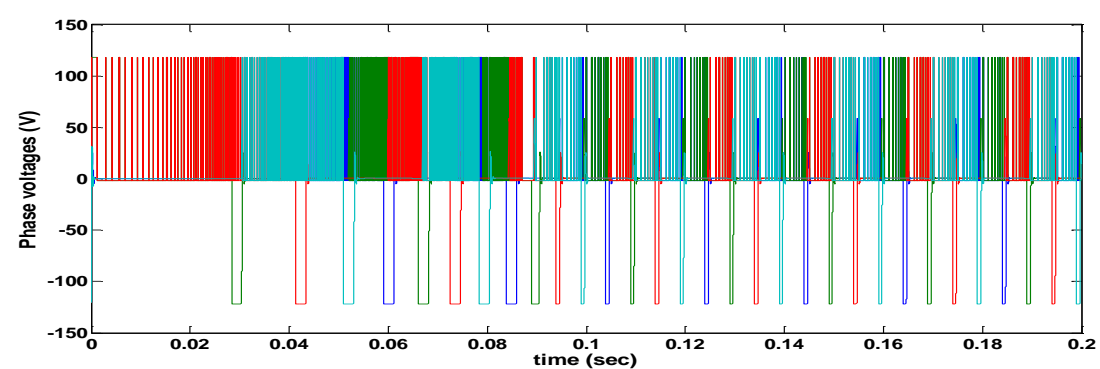

(c) Phase voltages 


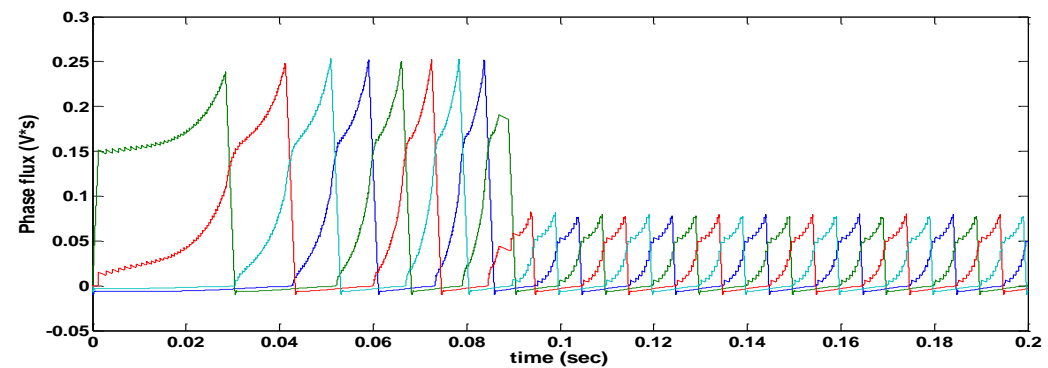

(d) Phase flux

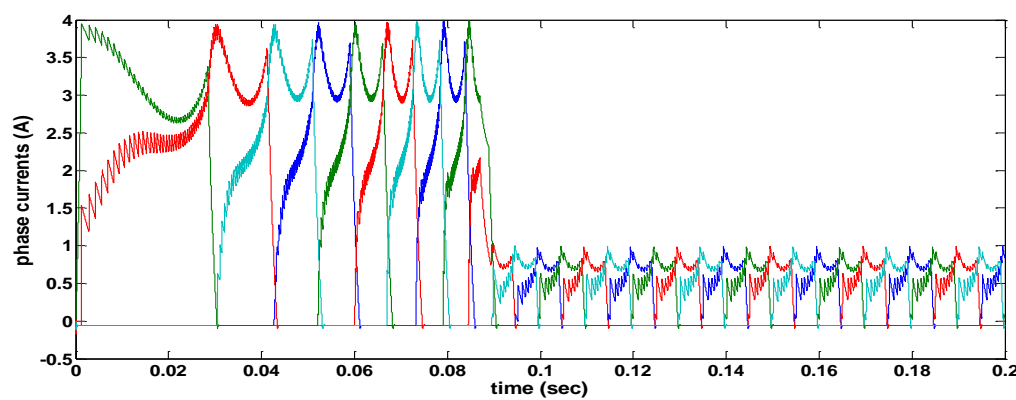

(e) Phase currents

Figure 6. Simulation results of DITC for Asymmetric converter at $\mathrm{N}=500 \mathrm{rpm}$ and $T_{\mathrm{L}}=1 \mathrm{Nm}$

\section{DITC with Four-Level Converter}

The four-level converter has additional charge capacitor $\mathrm{C}_{\mathrm{B}}$, power switch $\mathrm{Q}_{\mathrm{CD}}$ and diode $D_{C D}$ when compared with asymmetric converter. Four-level converter operates in four modes.

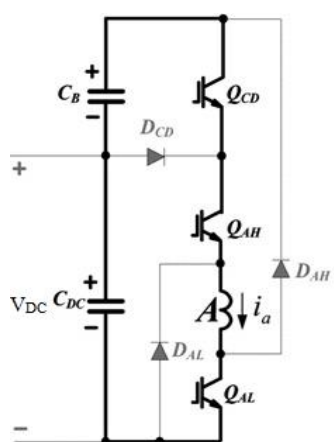

(a)

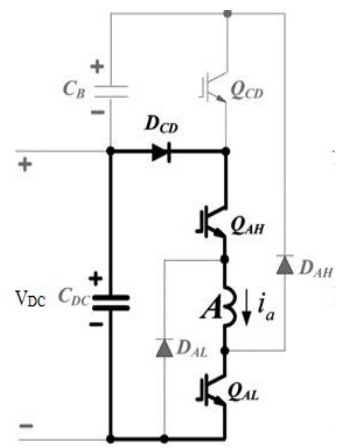

(b)

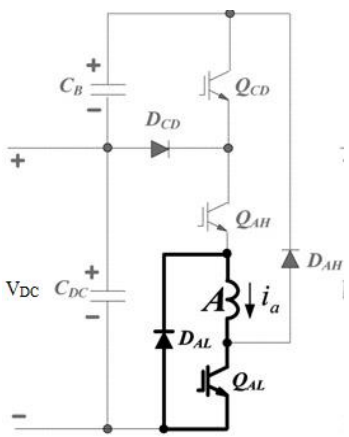

(c)

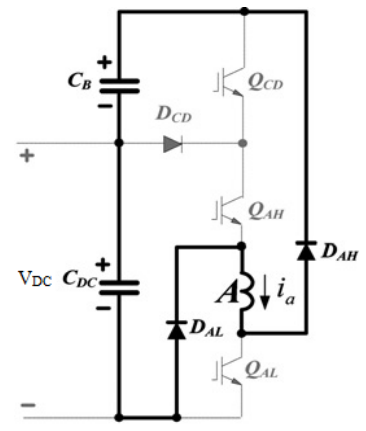

(d)

Figure 7. Operation modes of the Four-level converter

In mode 1 shown in Figure 7(a), three switches are turned on dc link voltage $V_{D C}$ and charged voltage $V_{B}$ are supplied to excite the phase winding, so current builds up at a faster rate. Hence this mode is known as fast magnetization mode and is represented by state 2 . When upper one switch as in Figure 7(b) and upper two switches Figure 7(c) are turned off then these modes are similar to magnetization and freewheeling modes of asymmetric converter. When all the three switches are turned off as shown in Figure $7(d)$ than $-\left(V_{D C}+V_{B}\right)$ is applied across the phase winding and the currents decreases to zero at faster rate. Hence this mode is known as fast demagnetization mode and is represented by state -2 .

DITC can be implemented for four-level converter by classifying inductance phase which is divided into three regions, as shown in Figure 8. 

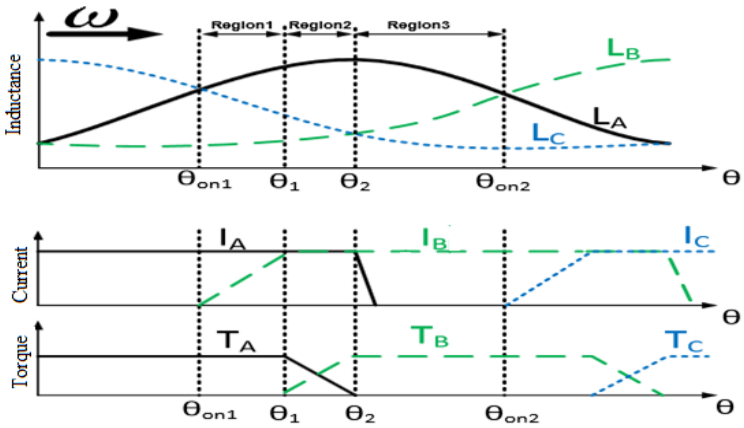

Figure 8. Classification of inductance regions for DITC

$\theta_{\text {on1 }}$ and $\theta_{\text {on2 }}$ are turn-on angle in the incoming and the next incoming phase, respectively. Here $\theta_{1}$ is a rotor position which is the initial point of overlap of the stator and rotor, and $\theta_{2}$ is the aligned position of inductance in the outgoing phase.

In region 1, slope of inductance in phase $A$ is high, whereas the slope of inductance in phase $B$ is very small, so majority of torque is produced by phase $A$. In region 2 , rotor is almost aligned with stator phase A where slope of inductance is low. Slope of inductance in phase B is increasing but it cannot produce output torque alone. So the main torque is produced by phase $\mathrm{B}$, and the rest is produced by phase A. In region 3, rotor starts moving away from the stator phase $A$. the slope of inductance is negative in this region which produces negative torque. Regions 1 and 2 are employed for DITC control of SRM in motoring mode [10].

Control scheme of the outgoing phase and incoming phase in region 1 and region 2 is shown in Figure 9. When the incoming phase is turned on the outgoing phase is set in freewheeling mode. As incoming phase inductance is building up slowly in region 1 state 2 is applied in order to supply reference torque, whereas in region 2 slope of inductance is more compared to region 1 so state 1 is sufficient in this case to supply reference torque After few instants when torque error crosses $\Delta \mathrm{e} 1$ than outgoing phase is changed to state 1 as incoming phase cannot supply complete torque. The incoming phase is kept in state 1 in both regions. If torque error crosses $\Delta \mathrm{e} 2$ then torque error is more, in order to make the output motor torque equal to reference torque value outgoing and incoming phases are changed to state 2 so that current increases at a faster rate and increases the phase torque. When torque error becomes negative then outgoing phase is set in fast demagnetization mode (state -2) and incoming phase is set in freewheeling mode (state 0) [10].

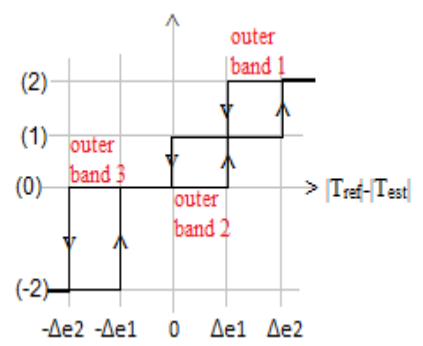

(a) Outgoing phase Region 1 and 2

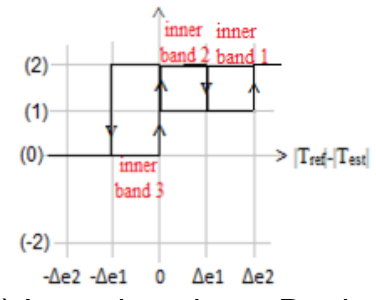

(b) Incoming phase Region 1

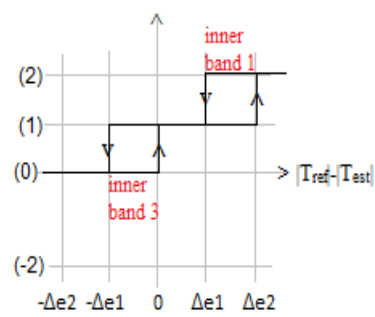

(c) Incoming phase Region 2

Figure 9. DITC scheme of four-level converter

\section{Simulation and Analysis of SRM Using DITC Scheme with Four-level Converter}

Simulink model of 4-phase 8/6 SRM using DITC scheme of four-level converter is shown in Figure 10. Actual speed is compared with the reference speed and the error is given to $\mathrm{PI}$ controller. The output of $\mathrm{PI}$ controller is reference torque. Estimated torque is compared with 
this reference torque and the error signal is given to a hysteresis torque controller which generates switching signals for the converter based on error. Torque is regulated within six hysteresis bands. The controller block in Figure 10 is depicted by a flow chart shown in Figure 11.

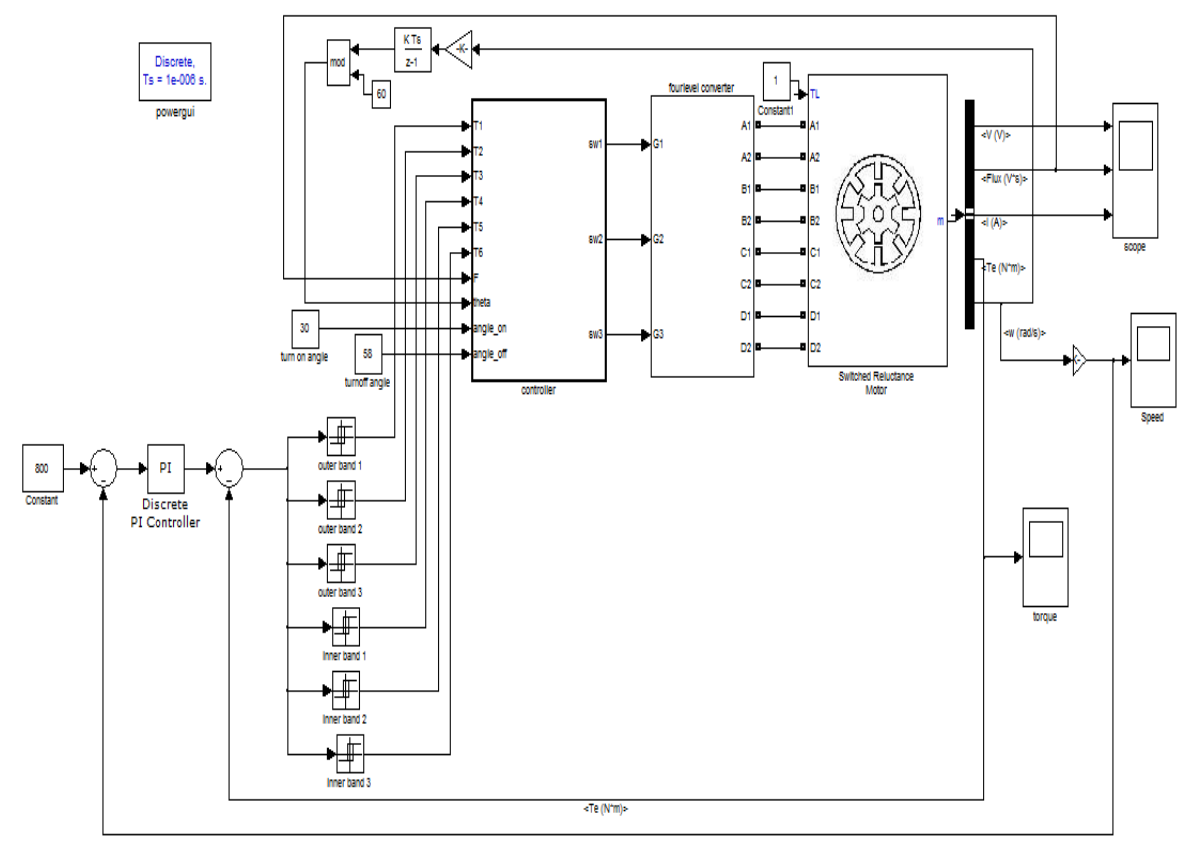

Figure 10. Simulink model of 8/6 SRM using DITC scheme of four-level converter

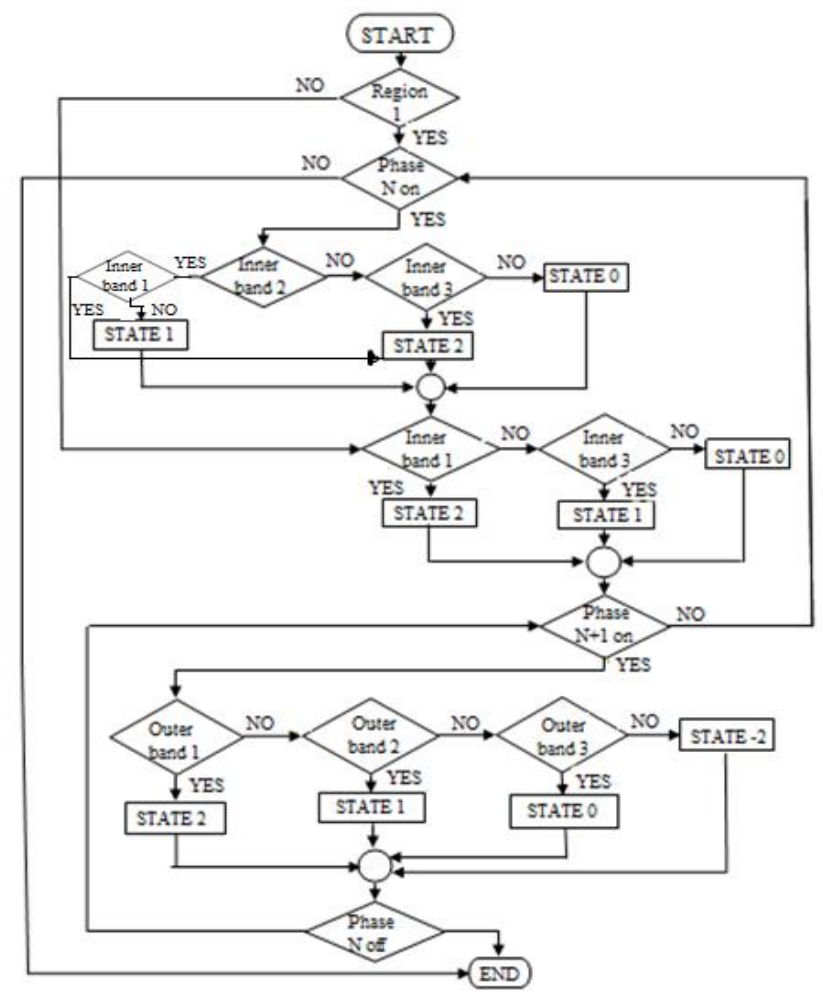

Figure 11. Flow chart representation of hysteresis torque controller for four-level converter 
The performance of the DITC based SRM drive using four-level converter is analyzed for a constant load torque of $1 \mathrm{Nm}$ and a reference speed of $800 \mathrm{rpm}$. Figure 12(a) shows the total torque. The torque is maintained at $4 \mathrm{Nm}$ till the steady state is reached. When the steady state is reached it is maintained at the load torque value i.e., $1 \mathrm{Nm}$. Torque ripple is $2.72 \%$ in this case. Thus by using four-level converter torque ripple is reduced when compared to an asymmetric converter. Figure 12(b) shows the speed response. Speed increases linearly and it settles at reference speed of $800 \mathrm{rpm}$ after $0.14 \mathrm{sec}$. Figure 12(c) shows the voltages of four phases. The voltage in each phase changes between $+240,+120 \mathrm{~V}, 0 \mathrm{~V}$ or $-240 \mathrm{~V}$ depending upon the torque error in order to maintain the total torque equal to the load torque. Figure 12(d) shows the flux of four phases. The maximum value of flux in acceleration period is $0.25 \mathrm{~Wb}$ and in the steady state the maximum flux value is $0.073 \mathrm{~Wb}$. Figure $12(\mathrm{e})$ shows the current waveform of all the four phases. The currents and flux linkage are proportional to each other so that they will vary almost similarly with respect to time. The maximum value of current in acceleration period is $3.9 \mathrm{~A}$ and in the steady state the maximum current value is $0.9 \mathrm{~A}$.

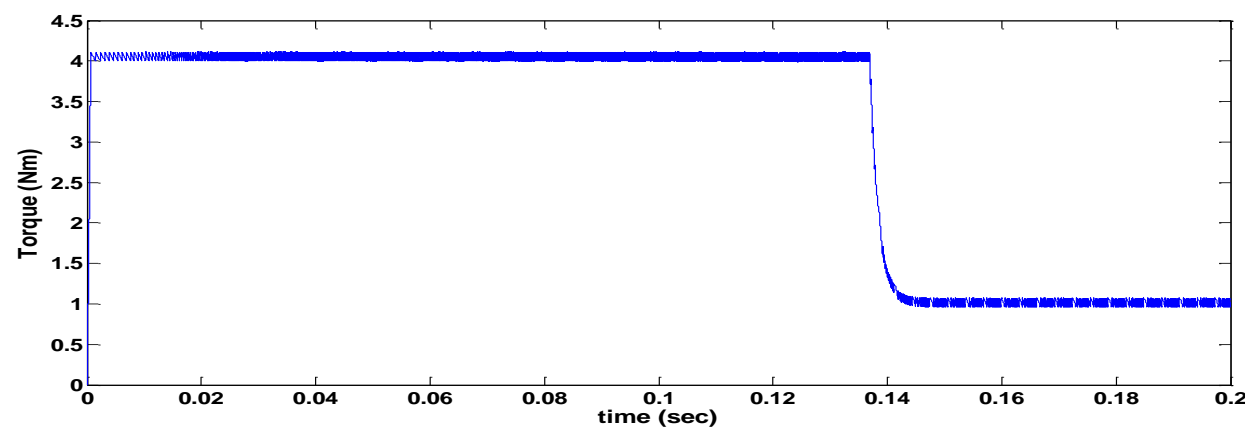

(a) Total torque

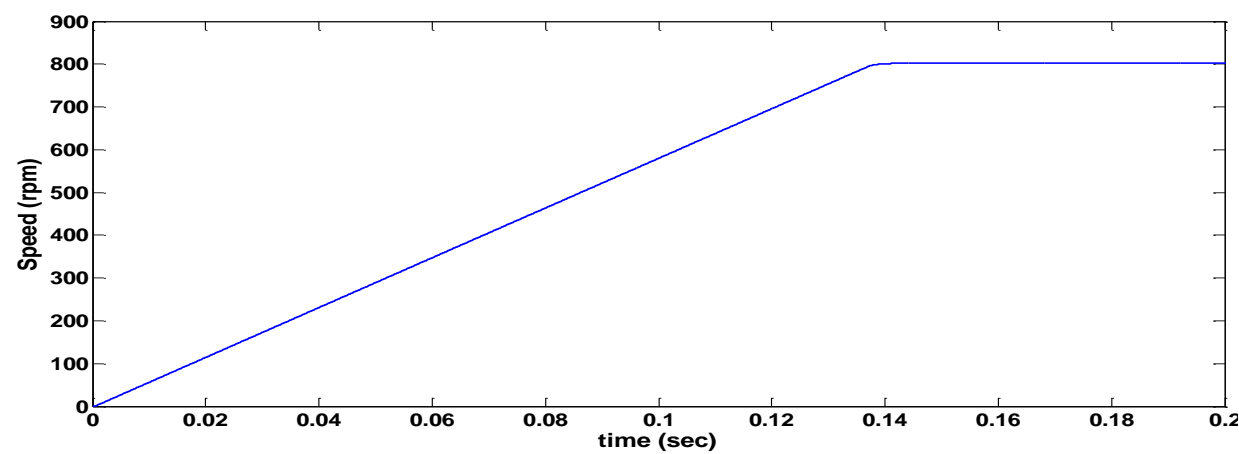

(b) Speed

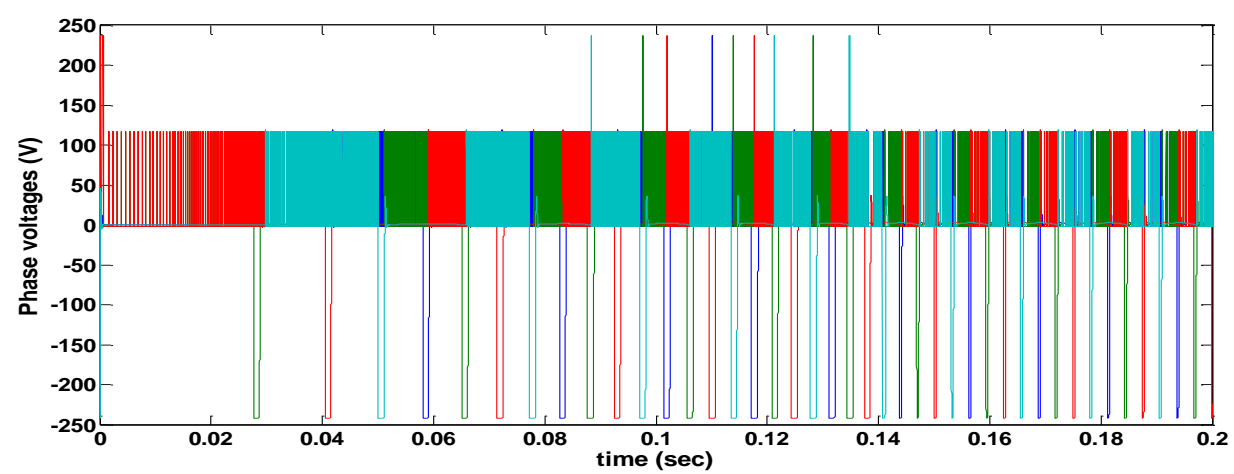

(c) Four phase voltages 


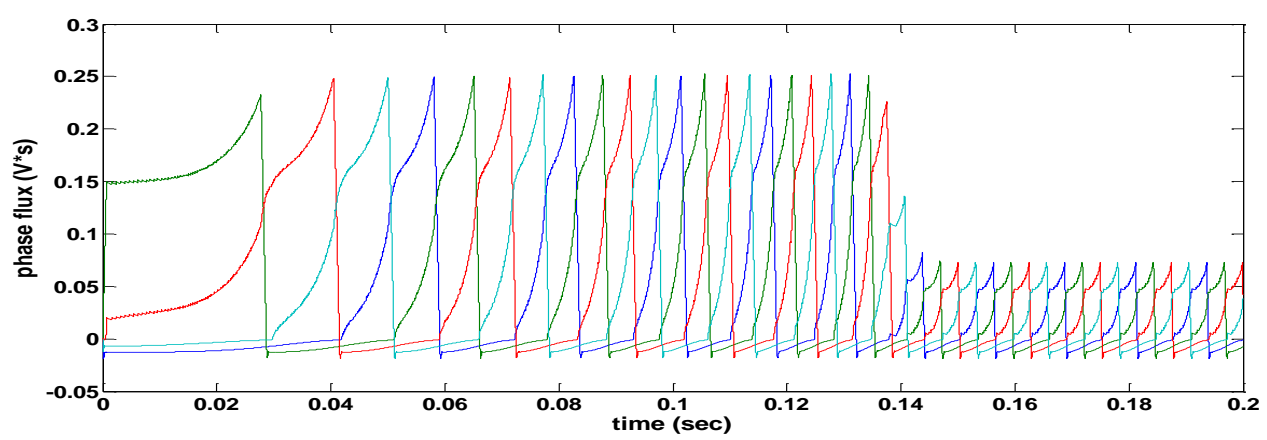

(d) Four phase flux

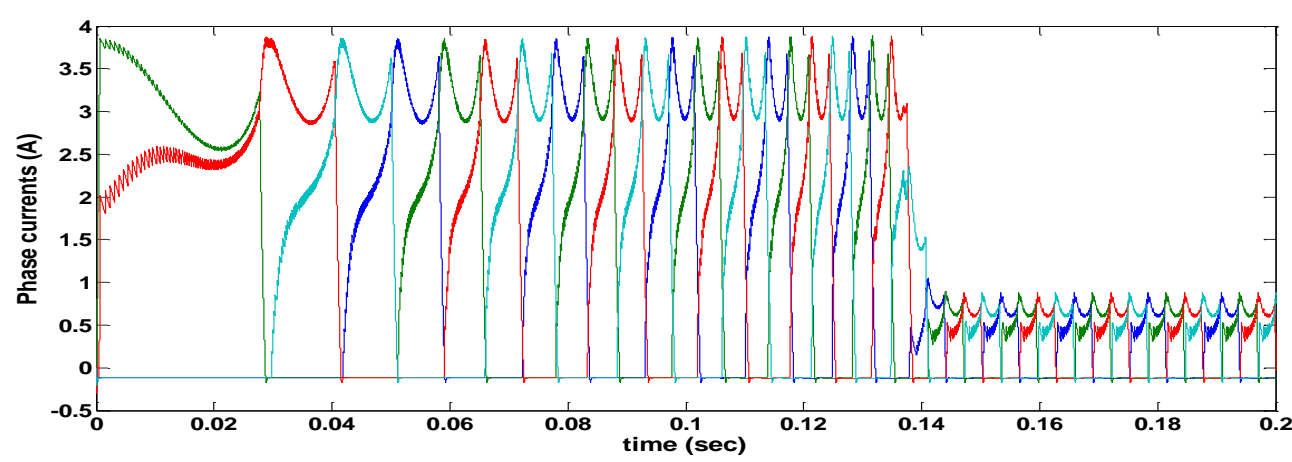

(e) Four phase currents

Figure 12. Simulation results of DITC for four-level converter at $N=800 \mathrm{rpm}$ and $T L=1 \mathrm{Nm}$

\section{Conclusion}

Torque ripple is high in SRM because of double saliency and highly nonlinear magnetic characteristics. This is serious drawback in SRM. By using DITC technique torque ripple can be minimized. This paper has analysed the variation of torque ripples in SRM with DITC technique for two converters namely Asymmetric converter and Four-level converter. From the simulations, it is observed that torque ripple obtained by using Four-level converter is almost reduced to half when compared to the torque ripple obtained by using Asymmetric converter. This is due to the fact that Four-level converter has additional fast magnetization and fast demagnetization compared to Asymmetric converter which has only magnetization and demagnetization states. So the current build up and decay time is less for four-level converter, because of this feature torque ripple is reduced. Thus, by employing DITC technique for fourlevel converter, torque ripple can be reduced to a greater extent as compared to asymmetric converter.

\section{References}

[1] R Krishnan. Switched Reluctance Motor Drives: modeling, simulation, analysis, designs and applications. CRC press, 2001.

[2] T Husain. Minimization of torque ripple in SRM drives. IEEE Transaction on Industrial Electronics, 2002; 49(1): 28-39.

[3] XD Xue, KWE Cheng, and NC Cheung. Evaluation of Torque Sharing Functions for Torque Ripple Minimization of Switched Reluctance Motor Drives in Electric Vehicles. Australasian Universities Power Engineering Conference 2008.

[4] XD Xue, KWE Cheng. Optimization and Evaluation of Torque-Sharing Functions for Torque Ripple Minimization in Switched Reluctance Motor Drives. IEEE transactions on Power Electronics, 2009; 24(9).

[5] RB Inderka and RW De Doncker. DITC-Direct instantaneous torque control of switched reluctance drives. International Confernce. Rec. IEEE-IAS Annual. Meeting, 2002: 3: 1605-1609.

[6] Fuengwarodsakul NH, Menne M, Inderka RB, De Doncker RW. High-dynamic four-quadrant switched reluctance drive based on DITC. IEEE Transaction on Industrial Applicatons. 2005, 41(5): 1232-1242. 
[7] J Castro, P Andrada and B Blanque. Minimization of torque ripple in switched reluctance motor drives using direct instantaneous torque control. International Conference on Renewable Energies and Power Quality. 2012.

[8] Rohit Suryadevara, BG Fernandes. Modified Direct Instantaneous Torque Control of Switched Reluctance Motor with High Torque per Ampere and Reduced Source Current Ripple". International Power Electronics Conference. 2014.

[9] DH Lee and JW Ahn. A Novel Four-Level Converter and Instantaneous Switching Angle Detector for High Speed SRM Drive. IEEE Transaction on Power Electronics. 2007; 22: 2034-2041.

[10] J Liang, DH Lee, and JW Ahn. Direct instantaneous torque control of switched reluctance machines using 4-level converters. IET Electrical Power Applications. 2009; 3: 313-323.

\section{Appendix:}

\section{Specifications of SRM}

\begin{tabular}{cc}
\hline Stator poles & 8 \\
Rotor poles & 6 \\
Voltage & $120 \mathrm{~V} \mathrm{DC}$ \\
Maximum current & $30 \mathrm{~A}$ \\
Maximum flux & $0.4 \mathrm{~Wb}$ \\
Aligned inductance & $110 \mathrm{mH}$ \\
Unaligned inductance & $10 \mathrm{mH}$ \\
Saturated aligned inductance & $0.15 \mathrm{mH}$ \\
\hline
\end{tabular}

